\title{
OPEN Resistance to insecticides and synergism by enzyme inhibitors in Aedes albopictus from Punjab, Pakistan
}

\author{
Hafiz Azhar Ali Khan
}

The widespread use of insecticides has ecological consequences such as emergence of insecticide resistance and environmental pollution. Aedes albopictus is a major vector of dengue virus in the Punjab province, Pakistan. Control of Ae. albopictus with insecticides along with source eradication is critical in the prevention and control of dengue fever but is threatened by the development of insecticide resistance. Here, field strains of Ae. albopictus from eight cities of Punjab were evaluated for resistance against temephos, deltamethrin and permethrin. For temephos, high resistance $\left(R R_{\mathrm{LC5}}>\right.$ tenfold $)$ was found in larvae of the Rawalpindi strain, moderate resistance $\left(R R_{\mathrm{LC5}}=\right.$ fiveto tenfold) in Multan, Faisalabad, Sialkot, Lahore and Sheikhupura strains, and low resistance $\left(R_{\mathrm{LC50}}<\right.$ fivefold) in Kasur and Sahiwal strains. In the case of deltamethrin, high resistance was seen in adults of the strain from Faisalabad, moderate resistance in the strains from Sialkot, Sheikhupura, Lahore and Kasur, and low resistance in Sahiwal, Multan and Rawalpindi strains. For permethrin, adults of all the field strains exhibited high levels of resistance. In synergism bioassays, toxicity of all the insecticides in the field strains significantly enhanced when tested in combination with piperonyl butoxide or $S, S, S$-tributylphosphorotrithioate, suggesting the probability of metabolic-based mechanisms of resistance. In conclusion, field strains of Ae. albopictus from Punjab exhibit resistance to temephos, deltamethrin and permethrin, which might be associated with metabolic mechanisms of resistance.

Arboviruses, viruses transmitted by mosquitoes or other arthropods, cause severe diseases and deaths in humans worldwide. These are transmitted by multiple species of insects and each species has its own importance depending upon their geographical distribution, virus carrying capacity, and their potential of virus transmission ${ }^{1}$. Aedes albopictus (Skuse) is an anthropophilic mosquito species with the potential to act as a competent vector of important arboviruses such as dengue, chikungunya, yellow fever, Rift Valley fever and Zika. Aedes albopictus has worldwide distribution ${ }^{2}$, which makes it an important factor for the transmission of arboviral-diseases in different parts of the world.

Of different arboviral-diseases, dengue fever has been considered as one of the most rapidly spreading diseases in the world with an estimate of 3.9 billion people in different countries at risk ${ }^{3}$. This disease has also affected different regions of Pakistan. In Pakistan, the first case of dengue fever was reported in 1994, and country's worst epidemics of dengue fever were observed between 2011-2013,5. Lack of vaccination is one of the major hurdles in the management of dengue fever. Although, a vaccine (Dengvaxia) to prevent dengue fever has been registered in several countries, it is not yet in widespread use and has certain safety concerns ${ }^{1,6}$. Aedes albopictus is one of the major vectors of dengue virus in Pakistan having wide distribution in different parts of the country. In the absence of vaccines and effective drugs for dengue fever, control of Ae. albopictus with insecticides coupled with breeding-source eradication is therefore absolutely critical in the prevention and control of dengue fever.

In Pakistan, control of Ae. albopictus is principally based on chemical measures coupled with community participation for larval source reduction. Although different alternative measures for Aedes mosquitoes such as the use of genetic manipulation, sterile insect techniques, and the use of endosymbionts such as Wolbachia that compete with dengue virus and hinders its reproduction have the potential to give satisfactory results, they are recommended/practiced in restricted locations worldwide. Since the development and adoption of new control measures are time taking processes, hence the current insecticide-based management strategies would be expected to play an important role in Aedes mosquitoes management for many years to come ${ }^{1}$. Currently, 


\begin{tabular}{|l|l|l|l|}
\hline Collection locality & Collection period & Collection site & Coordinate \\
\hline Multan & September, 2017 & Water cooler, tires & $30.1575^{\circ} \mathrm{N}, 71.5249^{\circ} \mathrm{E}$ \\
\hline Sahiwal & September, 2017 & Discarded small containers, flower pots, water air cooler & $30.6682^{\circ} \mathrm{N}, 73.1114^{\circ} \mathrm{E}$ \\
\hline Lahore & July, 2018 & Flower pots, tree holes, irrigation channel & $31.5204^{\circ} \mathrm{N}, 74.3587^{\circ} \mathrm{E}$ \\
\hline Sheikhupura & July, 2017 & Tree holes, water air cooler & $31.7167^{\circ} \mathrm{N}, 73.9850^{\circ} \mathrm{E}$ \\
\hline Kasur & September, 2018 & Tree holes, flower pots & $31.1179^{\circ} \mathrm{N}, 74.4408^{\circ} \mathrm{E}$ \\
\hline Faisalabad & August, 2018 & Tree holes, tires, water air cooler & $31.4504^{\circ} \mathrm{N}, 73.1350^{\circ} \mathrm{E}$ \\
\hline Sialkot & September, 2017 & Tree holes, irrigation channel, water air cooler & $32.4945^{\circ} \mathrm{N}, 74.5229^{\circ} \mathrm{E}$ \\
\hline Rawalpindi & August, 2018 & Tree holes, flower pots & $33.5651^{\circ} \mathrm{N}, 73.0169^{\circ} \mathrm{E}$ \\
\hline
\end{tabular}

Table 1. Collection history of Aedes albopictus field strains used for resistance monitoring and synergism experiments.

temephos (an organophosphate) through larviciding, and deltamethrin and permethrin (pyrethroids) through space and indoor residual sprays have been in wide use in Aedes mosquitoes control programs. In this scenario, wide use of insecticides is fraught with the rapid development of insecticide resistance and environmental pollution ${ }^{7,8}$.

Insecticidal bioassays in combination of enzyme inhibitors (e.g., S,S,S-tributylphosphorotrithioate (DEF or tribufos) and piperonyl butoxide $(\mathrm{PBO})$ ) to check their synergistic effect on insecticide toxicity is a rapid and inexpensive approach to provide clues regarding the possibility metabolic mechanisms of insecticide resistance ${ }^{9,10}$. Studies revealed that esterase- and/or oxidase-based mechanism of resistance could be present in insect species if toxicity of a particular insecticide is enhanced when used in combination with DEF, since DEF inhibits the activities of oxidases and esterases. Likewise, possibility of oxidase-based mechanism of resistance could be detected if the toxicity of an insecticide is synergized when used in combination with PBO, since it suppresses activities of oxidases ${ }^{9,11,12}$. Recently, development of insecticide resistance to organophosphate (temephos) and pyrethroid (deltamethrin and permethrin) insecticides have been reported in another important vector of dengue virus, Ae. aegypti (L.), from different areas of Punjab ${ }^{5}$, and bioassays in combination of PBO and DEF suggested the probability of metabolic mechanism of resistance associated with resistance to the organophosphate. Likewise, there are chances of resistance development in Ae. albopictus that may reduce the efficacy of current insecticide-based control programs. Therefore, present study was planned to investigate the possibility of insecticide resistance development to commonly used insecticides (temephos, deltamethrin and permethrin) in Ae. albopictus collected from the urban areas of Punjab, Pakistan. Furthermore, synergism bioassays by using PBO and DEF in combination with insecticides were also performed to find the clues about the presence of metabolic mechanisms of resistance in the putatively resistant strains of Ae. albopictus.

\section{Materials and methods}

Aedes albopictus strains. The study was conducted on Ae. albopictus strains collected from eight cities of the Punjab province, Pakistan, during 2017-2018 (Table 1). The cities were selected on the basis of dengue fever outbreaks in recent years and wide use of insecticides application for control of Aedes mosquitoes. A reference strain (Ref-S) of Ae. albopictus was also collected from an area of very low chemical application and reared in the laboratory for 20 generations in insecticide-free environment. Although not truly susceptible, the susceptibility of the Ref-S strain to insecticides was quite higher as compared to the field strains (see results section) and hence can be used as baseline for resistance monitoring ${ }^{13}$. Immature Ae. albopictus were collected from different breeding sites and transported to the laboratory. About 500-700 immature Ae. albopictus were used to start each colony. In laboratory these strains were reared by maintaining $26 \pm 1{ }^{\circ} \mathrm{C}, 65 \pm 5 \% \mathrm{r}$.h. and photoperiod of 12:12 (L:D) h. In the laboratory, the diet was consisted of fish food for larvae and $20 \%$ sucrose solution for adult mosquitoes, while female Ae. albopictus were bloodfed from an anesthetized mouse thrice a week following in accordance with relevant guidelines and regulations. The field strains were reared up to F1 or F2 generations before starting bioassays. The study/bioassay protocols used against Ae. albopictus were performed according to the standard guidelines and regulations, and approved by the bioethics committee of Institute of Agricultural Sciences, University of the Punjab, Lahore.

Insecticides and synergists. Bioassays were conducted by using technical-grade temephos (>95\%), deltamethrin (99.5\%), permethrin (98\%), PBO (98\%), and DEF (98\%) (ChemService Inc., West Chester, PA).

Bioassays. Bioassay methods have been described in detail elsewhere ${ }^{5}$. Briefly, toxicity of temephos was checked through larval bioassay in three replicates. A range of dilutions were prepared in acetone, while acetone alone was taken as a control. For Ref-S and field strains, the concentrations used were ranged between 0.01 to $0.32 \mu \mathrm{g} / \mathrm{ml}$ and 0.04 to $1.28 \mu \mathrm{g} / \mathrm{ml}$, respectively.

Bottle-bioassay method developed by the Centre for Disease Control (CDC) was followed to check the toxicity of deltamethrin and permethrin against female adults of Ae. albopictus ${ }^{9}$. Deltamethrin and permethrin were dissolved in acetone to prepare concentrations. These concentrations were used to coat $250 \mathrm{ml}$ glass bottles at the rate of $1 \mathrm{ml} /$ bottle. Control bottles were coated with acetone alone. Range of concentrations used were as 


\begin{tabular}{|c|c|c|c|c|c|c|c|c|}
\hline \multirow[b]{2}{*}{ Insecticide } & \multirow[b]{2}{*}{ Strain } & \multirow[b]{2}{*}{$\mathbf{n}$} & \multirow[b]{2}{*}{$\mathrm{KC}_{50}(95 \% \mathrm{CI})(\mu \mathrm{g} / \mathrm{ml})$} & \multicolumn{4}{|c|}{ Fit of probit line } & \multirow[b]{2}{*}{$\mathrm{RR}_{\mathrm{KC} 50}(95 \% \mathrm{CI})$} \\
\hline & & & & Slope (S.E) & $\chi^{2}$ & df & $p^{\varepsilon}$ & \\
\hline \multirow{9}{*}{ Deltamethrin } & Ref-S & 525 & $1.42(0.94-2.25)$ & $2.33(0.20)$ & 7.83 & 4 & 0.10 & 1 \\
\hline & Multan & 525 & $4.35(3.27-6.25)$ & $1.92(0.17)$ & 5.47 & 4 & 0.24 & $3.06(2.40-3.90)^{*}$ \\
\hline & Sahiwal & 525 & $4.97(3.70-7.35)$ & $1.83(0.17)$ & 5.15 & 4 & 0.27 & $3.50(2.70-4.51)^{\star}$ \\
\hline & Lahore & 450 & $13.91(9.58-27.98)$ & $2.06(0.24)$ & 3.96 & 3 & 0.27 & $9.80(7.29-13.12)^{*}$ \\
\hline & Sheikhupura & 525 & $18.55(15.36-23.35)$ & $1.96(0.19)$ & 1.81 & 4 & 0.77 & $13.06(10.07-16.88)^{*}$ \\
\hline & Kasur & 525 & $8.55(6.54-11.40)$ & $1.85(0.16)$ & 4.67 & 4 & 0.32 & $6.02(4.75-7.60)^{*}$ \\
\hline & Faisalabad & 525 & $12.69(10.31-16.18)$ & $1.53(0.15)$ & 1.21 & 4 & 0.88 & $8.94(6.80-11.70)^{*}$ \\
\hline & Sialkot & 525 & $7.13(5.75-9.22)$ & $1.54(0.16)$ & 3.14 & 4 & 0.54 & $5.02(3.79-6.63)^{\star}$ \\
\hline & Rawalpindi & 450 & $4.82(4.13-5.64)$ & $2.23(0.20)$ & 1.64 & 3 & 0.65 & $3.39(2.72-4.21)^{\star}$ \\
\hline \multirow{9}{*}{ Permethrin } & Ref-S & 525 & $0.60(0.40-0.90)$ & $2.41(0.22)$ & 6.69 & 4 & 0.15 & 1 \\
\hline & Multan & 450 & $7.28(6.06-8.81)$ & $1.82(0.19)$ & 2.61 & 3 & 0.46 & $12.13(9.56-15.45)^{*}$ \\
\hline & Sahiwal & 525 & $7.96(6.64-9.66)$ & $1.68(0.14)$ & 2.49 & 4 & 0.65 & $13.27(10.44-16.92)^{*}$ \\
\hline & Lahore & 450 & $6.85(5.75-8.34)$ & $1.99(0.21)$ & 0.70 & 3 & 0.87 & $11.42(9.00-14.53)^{*}$ \\
\hline & Sheikhupura & 525 & $8.50(6.81-11.21)$ & $1.55(0.15)$ & 1.27 & 4 & 0.87 & $14.19(10.62-18.97)^{*}$ \\
\hline & Kasur & 525 & $12.24(9.69-16.20)$ & $1.32(0.13)$ & 1.40 & 4 & 0.84 & $20.40(15.19-27.50)^{*}$ \\
\hline & Faisalabad & 525 & $8.69(6.98-11.10)$ & $1.33(0.13)$ & 1.69 & 4 & 0.79 & $14.48(11.00-19.13)^{*}$ \\
\hline & Sialkot & 525 & $15.47(11.99-21.38)$ & $1.28(0.14)$ & 2.59 & 4 & 0.63 & $25.78(18.69-35.69)^{*}$ \\
\hline & Rawalpindi & 525 & $12.99(10.58-16.54)$ & $1.56(0.15)$ & 1.07 & 4 & 0.90 & $21.65(16.57-28.40)^{*}$ \\
\hline
\end{tabular}

Table 2. Knock-down concentrations $\left(\mathrm{KC}_{50 \mathrm{~s}}\right)$ and resistance ratios $\left(\mathrm{RR}_{\mathrm{KC} 50}\right)$ of adults of Aedes albopictus strains against deltamethrin and permethrin. $\mathrm{RR}_{\mathrm{KC} 50}$, resistance ratio at $\mathrm{KC}_{50}=\left(\mathrm{KC}_{50}\right.$ of a field strain $) \div\left(\mathrm{KC}_{50}\right.$ of Ref-S). * significantly different from Ref-S based on $95 \%$ CIs of $\mathrm{RR}_{\mathrm{KC} 50}$ did not include $1^{39}$.

follows: 0.31 to $10 \mu \mathrm{g} / \mathrm{bottle}$ for deltamethrin against the Ref-S strain; 1 to $32 \mu \mathrm{g} / \mathrm{bottle}$ for deltamethrin against field strains; 0.125 to $4 \mu \mathrm{g} /$ bottle for permethrin against the Ref-S strain; 1 to $32 \mu \mathrm{g} /$ bottle for permethrin against field strains. In each coated bottle 25 unfed females ( 3 to 5 days old) were introduced and the knockdown effect recorded after $1 \mathrm{~h}$. After this period, females were shifted in insecticide free flasks. Additional details are provided in supplemental materials.

Synergism experiments. Synergism bioassays were performed as outlined in our previous report ${ }^{5}$. In brief, Ae. albopictus larvae (for temephos) or unfed females (for deltamethrin or permethrin) were exposed to $\mathrm{PBO}$ and DEF solutions for $1 \mathrm{~h}$. After exposure to synergists, larvae or adults were then exposed to different concentrations ( $n=25$ per concentration per replicate) of insecticides via the insecticide solution (for larvae against temephos) or insecticide-treated bottles (for adults against deltamethrin or permethrin) as stated in the bioassay section. Additional details are provided in supplemental materials.

Data analyses. Data of the knockdown effect and mortality were subjected to Probit analysis using the software PoloPlus ${ }^{14}$. Median knockdown concentrations $\left(\mathrm{KC}_{50 \mathrm{~s}}\right)$ for deltamethrin and permethrin were calculated from the data after $1 \mathrm{~h}$ exposure. Median lethal concentrations $\left(\mathrm{LC}_{50 \mathrm{~s}}\right)$ for temephos, deltamethrin and permethrin were determined from the mortality data after $24 \mathrm{~h}$ exposure. $\mathrm{KC}_{50 \mathrm{~s}}$ or $\mathrm{LC}_{50 \mathrm{~s}}$ values of field strains were divided with those of the Ref-S strain to get resistance ratios $\left(R_{K C 50}, R_{L C 50}\right)$. The ratios were classified according to the following scale: $\mathrm{RR}<5$ folds (low resistance); $\mathrm{RR}$ ranged from 5 to 10 folds (moderate resistance); RR $>10$ folds (high resistance) $)^{5,15}$.

Simple linear regression was performed to find the association between $\mathrm{LC}_{50}$ and $\mathrm{KC}_{50}$ values for deltamethrin or permethrin in eight field strains. The resultant slope vales were analyzed following the criterion of Flores, et al. ${ }^{16}$ : a slope value $\simeq 1$ indicates $\mathrm{LC}_{50} \simeq \mathrm{KC}_{50}$ and most of the knockdown mosquitoes are dead after $24 \mathrm{~h}$ exposure; a slope value $>1$ indicates the $\mathrm{LC}_{50}$ value is greater than the $\mathrm{KC}_{50}$ value most of the knockdown mosquitoes recovered after $24 \mathrm{~h}$ exposure and more insecticide concentration is needed to cause mortality of these mosquitoes ${ }^{16}$.

\section{Results}

The results of bottle-bioassays using adults of Ae. albopictus for estimating $\mathrm{KC}_{50}$ and corresponding $\mathrm{RR}$ values for deltamethrin and permethrin are presented in Table 2 . The results revealed the highest susceptibility of the Ref-S strain to deltamethrin and permethrin with $\mathrm{KC}_{50}$ values 1.42 and $0.60 \mu \mathrm{g} / \mathrm{ml}$, respectively. $\mathrm{KC}_{50}$ values of different field strains ranged from 4.35 to $18.55 \mu \mathrm{g} / \mathrm{ml}$ for deltamethrin, and 6.85 to $15.47 \mu \mathrm{g} / \mathrm{ml}$ for permethrin. Field strains showed significant levels of RR values at $\mathrm{KC}_{50}$ level when compared with the Ref-S strain, based on the $95 \%$ CIs of RR values did not include 1. In the case of deltamethrin, Multan, Rawalpindi and Sahiwal strains exhibited low resistance (RR 3.06, 3.39 and 3.50 fold, respectively), Sialkot, Kasur, Faisalabad and Lahore moderate resistance (RR 5.02, 6.02, 8.94 and 9.80 fold, respectively), and high resistance in the strain of Sheikhupura (13.06 fold) (Table 2). 


\begin{tabular}{|c|c|c|c|c|c|c|c|c|}
\hline \multirow[b]{2}{*}{ Insecticide } & \multirow[b]{2}{*}{ Strain } & \multirow[b]{2}{*}{$\mathbf{n}$} & \multirow[b]{2}{*}{$\mathrm{LC}_{50}(95 \% \mathrm{CI})(\mu \mathrm{g} / \mathrm{ml})$} & \multicolumn{4}{|c|}{ Fit of probit line } & \multirow[b]{2}{*}{$\mathrm{RR}_{\mathrm{LC} 50}(95 \% \mathrm{CI})^{*}$} \\
\hline & & & & Slope (S.E) & $\chi^{2}$ & df & $p^{\varepsilon}$ & \\
\hline \multirow{9}{*}{ Temephos } & Ref-S & 525 & $0.05(0.04-0.07)$ & $2.88(0.24)$ & 4.79 & 4 & 0.31 & 1 \\
\hline & Multan & 525 & $0.30(0.26-0.35)$ & $2.26(0.20)$ & 2.84 & 4 & 0.58 & $6.00(4.47-6.79)$ \\
\hline & Sahiwal & 600 & $0.17(0.13-0.22)$ & $2.59(0.19)$ & 8.46 & 5 & 0.13 & $3.40(2.57-3.79)$ \\
\hline & Lahore & 450 & $0.40(0.34-0.46)$ & $2.28(0.20)$ & 1.04 & 3 & 0.79 & $8.00(5.92-8.90)$ \\
\hline & Sheikhupura & 525 & $0.41(0.35-0.48)$ & $2.26(0.21)$ & 1.37 & 4 & 0.85 & $8.20(6.03-9.13)$ \\
\hline & Kasur & 525 & $0.16(0.14-0.19)$ & $1.97(0.16)$ & 1.06 & 4 & 0.90 & $3.20(2.38-3.64)$ \\
\hline & Faisalabad & 525 & $0.30(0.23-0.38)$ & $2.68(0.24)$ & 5.72 & 4 & 0.22 & $6.00(4.51-6.65)$ \\
\hline & Sialkot & 525 & $0.39(0.32-0.49)$ & $1.97(0.23)$ & 0.36 & 4 & 0.99 & $7.80(5.52-9.17)$ \\
\hline & Rawalpindi & 525 & $0.64(0.51-0.85)$ & $1.48(0.15)$ & 2.85 & 4 & 0.58 & $12.80(9.59-17.03)$ \\
\hline \multirow{9}{*}{ Deltamethrin } & Ref-S & 525 & $1.48(1.13-1.92)$ & $2.88(0.22)$ & 7.89 & 4 & 0.10 & 1 \\
\hline & Multan & 450 & $4.66(3.99-5.56)$ & $2.31(0.22)$ & 2.35 & 3 & 0.50 & $3.15(2.55-3.89)$ \\
\hline & Sahiwal & 450 & $4.20(3.51-5.15)$ & $1.88(0.19)$ & 2.65 & 3 & 0.45 & $2.84(2.25-3.58)$ \\
\hline & Lahore & 450 & $11.22(8.08-18.90)$ & $1.96(0.22)$ & 3.27 & 3 & 0.35 & 7.58 (5.82-9.89) \\
\hline & Sheikhupura & 525 & $11.11(8.70-14.69)$ & $2.06(0.17)$ & 4.62 & 4 & 0.33 & $7.51(6.07-9.30)$ \\
\hline & \begin{tabular}{|l|} 
Kasur \\
\end{tabular} & 525 & $11.56(9.50-14.47)$ & $1.60(0.15)$ & 0.31 & 4 & 0.99 & $7.82(6.10-10.01)$ \\
\hline & Faisalabad & 525 & $28.84(21.52-43.54)$ & $1.44(0.17)$ & 0.52 & 4 & 0.97 & $19.50(13.49-28.19)$ \\
\hline & Sialkot & 525 & $9.52(7.63-12.59)$ & $1.63(0.17)$ & 0.67 & 4 & 0.95 & $6.44(4.86-8.52)$ \\
\hline & Rawalpindi & 450 & $7.36(5.92-9.60)$ & $1.52(0.18)$ & 1.82 & 3 & 0.61 & $4.97(3.79-6.53)$ \\
\hline \multirow{9}{*}{ Permethrin } & Ref-S & 525 & $0.54(0.43-0.68)$ & $2.31(0.18)$ & 4.80 & 4 & 0.31 & 1 \\
\hline & Multan & 450 & $11.82(8.58-18.16)$ & $2.39(0.23)$ & 5.10 & 3 & 0.16 & $21.89(17.57-27.36)$ \\
\hline & Sahiwal & 525 & $8.71(6.54-12.07)$ & $1.81(0.15)$ & 5.51 & 4 & 0.24 & $16.13(12.80-20.41)$ \\
\hline & Lahore & 450 & $8.83(7.35-11.05)$ & $1.98(0.21)$ & 2.18 & 3 & 0.54 & $16.35(12.74-21.05)$ \\
\hline & Sheikhupura & 525 & $6.44(4.28-11.53)$ & $1.48(0.14)$ & 7.72 & 4 & 0.10 & $11.93(9.06-15.77)$ \\
\hline & Kasur & 525 & $16.19(12.00-24.20)$ & $1.80(0.17)$ & 5.10 & 4 & 0.28 & $29.98(23.19-38.38)$ \\
\hline & \begin{tabular}{|l} 
Faisalabad \\
\end{tabular} & 525 & $18.08(14.10-23.48)$ & $1.39(0.15)$ & 2.71 & 4 & 0.61 & $33.48(24.39-46.10)$ \\
\hline & Sialkot & 525 & $37.14(25.74-64.56)$ & $1.25(0.16)$ & 2.57 & 4 & 0.63 & $68.78(43.10-110.06)$ \\
\hline & Rawalpindi & 525 & $19.50(14.80-24.16)$ & $1.27(0.14)$ & 2.18 & 4 & 0.70 & $36.11(25.49-51.31)$ \\
\hline
\end{tabular}

Table 3. Lethal concentrations $\left(\mathrm{LC}_{50 \mathrm{~s}}\right)$ and resistance ratios $\left(\mathrm{RR}_{\mathrm{LC} 50}\right)$ of Aedes albopictus larvae against temephos, and adults against deltamethrin and permethrin. $\mathrm{RR}_{\mathrm{LC5} 50}$, resistance ratio at $\mathrm{LC}_{50}=\left(\mathrm{LC}_{50}\right.$ of a field strain $) \div\left(\mathrm{LC}_{50}\right.$ of Ref-S $)$. ${ }^{*}$ Significantly different from Ref-S based on $95 \%$ CIs of $\mathrm{RR}_{\mathrm{LC} 50}$ did not include $1^{39}$.

Table 3 displays $\mathrm{LC}_{50}$ values and corresponding $\mathrm{RR}$ values obtained for temephos (against larvae), deltamethrin and permethrin (against adults) in different strains of Ae. albopictus. All the insecticides showed the highest toxicity to the Ref-S strain with $\mathrm{LC}_{50}$ values $0.05,1.48$ and $0.54 \mu \mathrm{g} / \mathrm{ml}$ for temephos, deltamethrin and permethrin, respectively. The $\mathrm{LC}_{50}$ values for different field strains ranged from 0.17 to $0.64 \mu \mathrm{g} / \mathrm{ml}$ for temephos, 4.20 to $28.84 \mu \mathrm{g} / \mathrm{ml}$ for deltamethrin, and 6.44 to $37.14 \mu \mathrm{g} / \mathrm{ml}$ for permethrin. High resistance to temephos was found in the Rawalpindi strain (RR 12.80 fold), moderate resistance in Multan (RR 6.00 fold), Faisalabad (RR 6.00 fold), Sialkot (RR 7.80 fold), Lahore (RR 8.00 fold) and Sheikhupura (RR 8.20 fold) strains, and low resistance in Kasur (RR 3.20 fold) and Sahiwal (RR 3.40 fold) strains. In the case of deltamethrin, high resistance was seen in the strain of Faisalabad (RR 19.50 fold), moderate resistance in the strains of Sialkot (RR 6.44 fold), Sheikhupura (RR 7.51 fold), Lahore (RR 7.58 fold) and Kasur (RR 7.82 fold), and low resistance in Sahiwal (RR 2.84 fold), Multan (RR 3.51 fold) and Rawalpindi (RR 4.97 fold) strains. For permethrin, all the field strains exhibited high resistance with $R R$ values ranged from 11.93 to 68.78 fold (Table 3 ).

Regression analysis between $\mathrm{RR}_{\mathrm{LC} 50}$ and $\mathrm{RR}_{\mathrm{KC} 50}$ for deltamethrin and permethrin is shown in Fig. 1. For deltamethrin, the slope value 0.73 indicates that majority of the knockdown mosquitoes failed to recover after $24 \mathrm{~h}$. In contrast, the slope value 2.99 for permethrin revealed that most of the mosquitoes recovered after knockdown and a higher concentration of permethrin is required to eventually kill mosquitoes (Fig. 1).

The results of synergism bioassays against Ref-S and selected field strains are shown in Table 4 . The data revealed that the toxicity of all the insecticides in the Ref-S strain did not change significantly when bioassayed in the presence of either PBO or DEF. The synergism ratios were non-significant based on 95\% CIs of SRs include 1. In the case of field strains, toxicity of all the insecticides enhanced significantly when bioassayed in the presence of PBO or DEF (based on synergism ratio test and non-overlapping 95\% CIs of LC50 values), suggesting the possibility of metabolic mechanism of resistance. Toxicity of temephos against larvae of Ae. albopictus enhanced 2.25 and 2.66 fold in the presence of DEF and PBO, respectively. Similarly, toxicity of deltamethrin enhanced by 2.64 fold $(+\mathrm{DEF})$ and 2.07 fold $(+\mathrm{PBO})$, while toxicity of permethrin increased by 1.94 fold $(+\mathrm{DEF})$ and 2.62 fold (+ PBO) against adults of Ae. albopictus (Table 4). 


\section{Deltamethrin}
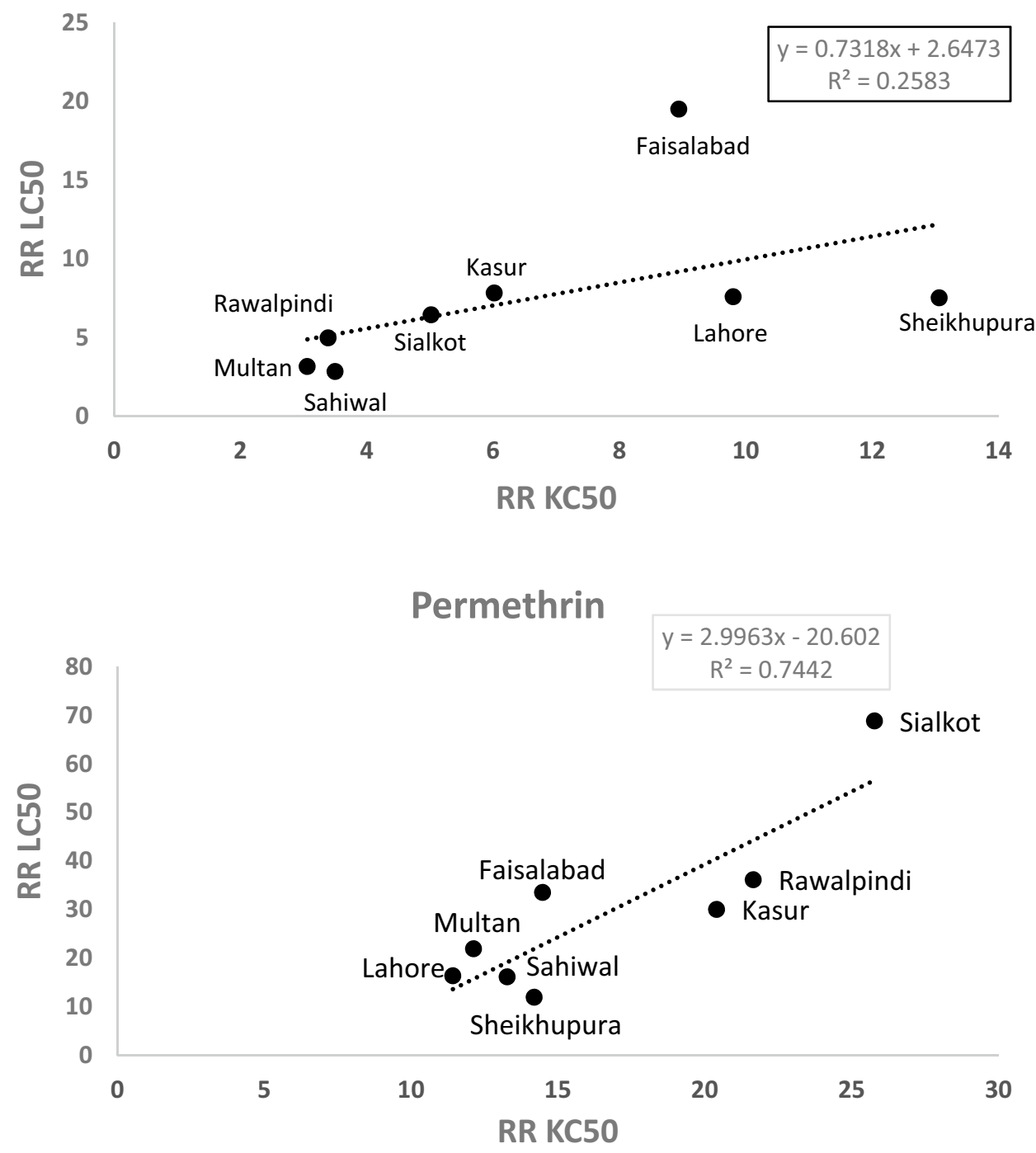

Figure 1. Simple linear regression between LC50 and KC50 values of adult Ae. albopictus of different field strains against deltamethrin or permethrin.

\section{Discussion}

Control failure of insect pests due to insecticide resistance often results in high dosage of insecticides, which ultimately pollute the environment ${ }^{17,18}$. The present study provides an evidence of resistance development to temephos, deltamethrin and permethrin in Ae. albopictus collected from different cities of the province Punjab. The selected cities have reported cases of dengue fever every year since the country's major epidemic in 2011. For this reason, the use of insecticides has been most frequent to control dengue mosquitoes in order to combat dengue fever epidemics, which might be the leading cause of resistance development in Ae. albopictus. Insecticides from different classes are heavily used in Punjab for the management of different insect pests, including Ae. albopictus. As a consequence, a number of studies have reported development of insecticide resistance in different disease vectors from Pakistan such as Musca domestica L. ${ }^{19,20}$ Ae. aegypti ${ }^{5,21,22}$, Culex quinquefasciatus $\mathrm{Say}^{23}$, Anopheles spp. ${ }^{24,25}$, and Periplaneta americana L. ${ }^{26}$.

Previously, we have reported resistance development in Ae. albopictus from cropping areas of Punjab as a consequence of indirect exposure to different agrochemicals ${ }^{27}$; however, there are limited reports of resistance development in Ae. albopictus from urban areas. For instance, Arslan, et al. ${ }^{22}$ reported the probability of resistance to deltamethrin and permethrin in Ae. albopictus from Rawalpindi. Similarly, Mohsin, et al. ${ }^{21}$ reported probability of resistance to different insecticides in Ae. albopictus from the Lahore city of Punjab. However, the scope of both studies, in our opinion, was limited since mosquitoes were sampled from only one location in each study. Therefore, it was the need to explore other important areas of the province with dengue positive cases every year. In our study, we examined insecticide resistance in more detail by determining resistance ratios in 


\begin{tabular}{|c|c|c|c|c|c|c|c|}
\hline \multirow[b]{2}{*}{ Strain } & \multirow[b]{2}{*}{ Treatment } & \multirow[b]{2}{*}{$\mathrm{LC}_{50}(95 \% \mathrm{CI})(\mu \mathrm{g} / \mathrm{ml})$} & \multicolumn{4}{|c|}{ Fit of probit line } & \multirow[b]{2}{*}{$\operatorname{SRE}(95 \% \mathrm{CI})$} \\
\hline & & & Slope (S.E) & $\chi^{2}$ & df & $p^{\varepsilon}$ & \\
\hline Ref-S & Temephos & $0.05(0.04-0.07)$ & $2.88(0.24)$ & 4.79 & 4 & 0.31 & \\
\hline Ref-S & Temephos + DEF & $0.05(0.03-0.06)^{\mathrm{ns}}$ & $2.42(0.18)$ & 4.24 & 4 & 0.37 & $1.00(0.89-1.32)$ \\
\hline Ref-S & Temephos + PBO & $0.06(0.04-0.07)^{\mathrm{ns}}$ & $2.69(0.20)$ & 6.94 & 4 & 0.14 & $0.84(0.76-1.11)$ \\
\hline Ref-S & Deltamethrin & $1.48(1.13-1.92)$ & $2.88(0.22)$ & 7.89 & 4 & 0.10 & - \\
\hline Ref-S & Deltamethrin + DEF & $1.25(0.92-1.70)^{\mathrm{ns}}$ & $2.51(0.19)$ & 9.05 & 4 & 0.06 & $1.18(0.97-1.43)$ \\
\hline Ref-S & Deltamethrin + PBO & $1.31(0.98-1.73)^{\mathrm{ns}}$ & $2.13(0.17)$ & 6.43 & 4 & 0.17 & $1.13(0.92-1.38)$ \\
\hline Ref-S & Permethrin & $0.54(0.43-0.68)$ & $2.31(0.18)$ & 4.80 & 4 & 0.31 & - \\
\hline Ref-S & Permethrin + DEF & $0.56(0.42-0.76)^{\mathrm{ns}}$ & $2.27(0.17)$ & 7.65 & 4 & 0.11 & $0.96(0.77-1.18)$ \\
\hline Ref-S & Permethrin + PBO & $0.49(0.36-0.67)^{\mathrm{ns}}$ & $2.49(0.19)$ & 8.85 & 4 & 0.06 & $1.10(0.89-1.34)$ \\
\hline Rawalpindi & Temephos & $0.64(0.51-0.85)$ & $1.48(0.15)$ & 2.85 & 4 & 0.58 & \\
\hline Rawalpindi & Temephos + DEF & $0.29(0.23-0.38)^{*}$ & $1.35(0.14)$ & 2.60 & 4 & 0.63 & $2.25(1.56-3.25)^{\star *}$ \\
\hline Rawalpindi & Temephos + PBO & $0.24(0.19-0.32)^{*}$ & $1.38(0.14)$ & 2.31 & 4 & 0.68 & $2.66(1.87-3.78)^{\star *}$ \\
\hline Faisalabad & Deltamethrin & $28.84(21.52-43.54)$ & $1.44(0.17)$ & 0.52 & 4 & 0.97 & - \\
\hline Faisalabad & Deltamethrin + DEF & $10.94(8.26-15.98)^{*}$ & $1.31(0.14)$ & 0.92 & 4 & 0.92 & $2.64(1.64-4.24)^{\star *}$ \\
\hline Faisalabad & Deltamethrin + PBO & $13.92(10.46-19.22)^{*}$ & $1.45(0.17)$ & 2.08 & 4 & 0.72 & $2.07(1.28-3.35)^{\star *}$ \\
\hline Sialkot & Permethrin & $37.14(25.74-64.56)$ & $1.25(0.16)$ & 2.57 & 4 & 0.63 & \\
\hline Sialkot & Permethrin + DEF & $19.17(14.65-24.35)^{*}$ & $1.30(0.15)$ & 1.12 & 4 & 0.89 & $1.94(1.13-3.33)^{\star *}$ \\
\hline Sialkot & Permethrin $+\mathrm{PBO}$ & $14.18(10.53-20.87)^{*}$ & $1.60(0.15)$ & 4.39 & 4 & 0.36 & $2.62(1.59-4.31)^{* *}$ \\
\hline
\end{tabular}

Table 4. Toxicity of temephos, deltamethrin, and permethrin with or without synergist in Aedes albopictus strains. $\mathfrak{E S R}$, synergism ratio $=\left(\mathrm{LC}_{50}\right.$ of temephos, deltamethrin or permethrin alone $) \div\left(\mathrm{LC}_{50}\right.$ of temephos, deltamethrin or permethrin plus PBO or DEF). ns, non-significant $(p>0.05)$ based on overlapping $95 \%$ CI of $\mathrm{LC}_{50}$ values of insecticides plus $\mathrm{PBO}$ or DEF when compared with that of the $\mathrm{LC}_{50}$ of insecticide alone. ${ }^{*}$ Significant SR, 95\% CIs of SR did not include $1^{39}$.

Ae. albopictus from eight major cities with respect to dengue fever incidence, and also studied the possibility of metabolic mechanism of resistance.

Pyrethroids such as deltamethrin and permethrin are dominant insecticides for the management of urban insect pests in residential environments. The results of the present study revealed low to high levels of resistance to deltamethrin and high levels of resistance to permethrin in different field strains of Ae. albopictus. In addition, regression analysis was performed to find the association between $\mathrm{LC}_{50}$ and $\mathrm{KC}_{50}$ values for deltamethrin or permethrin in different field strains. For deltamethrin, the slope value indicated that majority of the knockdown mosquitoes failed to recover after $24 \mathrm{~h}$. In contrast, the slope value for permethrin revealed that most of the mosquitoes recovered after knockdown and a higher concentration of permethrin was required to eventually kill mosquitoes. These insecticides are widely used in Punjab to combat mosquitoes. The most probable reason for resistance Ae. albopictus could be the fact of usage of these insecticides in different forms such as fogging, indoor residual sprays, mosquito coils against Aedes mosquitoes in order to protect from dengue fever ${ }^{5}$. Furthermore, injudicious use of pyrethroid insecticides for different insect pests in urban settings ${ }^{19}$ could also be responsible for resistance development in different strains of Ae. albopictus. Recently, we have reported resistance to permethrin and deltamethrin in Ae. aegypti from 12 cities (Faisalabad, Gujranwala, Lahore, Multan, Okara, Pattoki, Rawalpindi, Sahiwal, Sargodha, Sheikhupura, Sialkot and Kasur) of Punjab, Pakistan ${ }^{5}$. Except the Okara strain, all field strains exhibited high levels of resistance to permethrin. In case of deltamethrin, low levels of resistance were found in Multan, Okara and Sahiwal strains, moderate levels of resistance in Sialkot, Gujranwala and Sargodha strains, and high levels of resistance in Kasur, Pattoki, Lahore, Sheikhupura, Faisalabad and Rawalpindi. Previously, resistance to pyrethroid in Aedes mosquitoes has also been reported worldwide ${ }^{28-32}$.

In the present study, low to moderate levels of resistance to temephos were found in seven field strains, while the Rawalpindi strain exhibited high resistance to temephos. In Punjab, temephos is the most widely used as larvicide to manage larvae of Aedes mosquitoes that might be responsible for resistance development to temephos in Ae. albopictus. Temephos resistance in Ae. aegypti has also been reported from different cities (stated above) of Punjab $^{5}$. Of these, high levels of resistance were found in Gujranwala, Lahore, Kasur, Rawalpindi and Faisalabad strains, moderate levels of resistance in Okara, Sahiwal, Pattoki, Sialkot and Sheikhupura, and low levels of resistance in Sargodha and Multan. There are variable reports of resistance development to temephos in Ae. albopictus from different areas of the world. For instance, Ponlawat, et al. ${ }^{32}$ reported low levels of resistance to temephos in Ae. albopictus from different localities of Thailand. Larvae of Ae. albopictus from Selangor, Malaysia were found to be highly resistant to temephos ${ }^{33}$. In contrast, larvae of Ae. albopictus from Central Africa were found to be susceptible to temephos ${ }^{34}$. The different expression of resistance might be due to differences in geographic origin of Ae. albopictus strains, insecticide exposure histories and/or different environmental conditions.

Insecticidal bioassays in combination of enzyme inhibitors (e.g., PBO or DEF) to check their synergistic effect on insecticide toxicity is a rapid and inexpensive approach to provide clues regarding the possibility metabolic mechanisms of insecticide resistance ${ }^{9,10}$. Studies revealed that esterase- and/or oxidase-based mechanism of resistance could be present in insect species if toxicity of a particular insecticide is enhanced when used in 
combination with DEF, since DEF inhibits the activities of oxidases and esterases. Likewise, possibility of oxidasebased mechanism of resistance could be detected if the toxicity of an insecticide is synergized when used in combination with PBO, since it suppresses activities of oxidases ${ }^{9,11,12}$. In the present study, toxicity of temephos, deltamethrin and permethrin have been evaluated in combination with PBO or DEF against Ref-S and selected field strains of Ae. albopictus to check the possibility of metabolic mechanisms of resistance. The results showed that there was no synergistic effect of all the insecticides when checked against Ref-S. strain. It was expected, since Ref-S strain has been maintained in insecticide free environment. However, there was a significant synergistic effect of PBO and DEF on the toxicity of all the insecticides in field strains of Ae. albopictus. These results indicate the possibility of esterase- and oxidase-based mechanisms of resistance linked with insecticide resistance in field strains. Both of these enzyme inhibitors have also been reported to enhance toxicity of temephos in Ae. aegypti from Cucuta ${ }^{35}$ and in different field strains of Ae. aegypti from Punjab, Pakistan ${ }^{5}$.

Resistance to pyrethroid insecticides in insect pests can be due to the enhanced activities of metabolic enzymes and/or modification to the target site of these insecticides. Sayyed, et al. ${ }^{12}$ reported the synergistic effect of PBO and DEF on the toxicity of deltamethrin in Chrysoperla carnea (Stephens). In contrast to the present study, toxicity of deltamethrin and permethrin did not synergize by enzyme inhibitors in field strains of $A$ e. aegypti $i^{5}$.In the present study, the Sialkot strain showed about 69 fold RR at $\mathrm{LC}_{50}$ level, and its toxicity was enhanced by $<$ threefold in the presence of PBO or DEF. This high level of resistance to permethrin indicates the possibility of altered target site mechanism responsible for resistance to permethrin. Smith, et al. ${ }^{36}$ reported metabolic detoxification and altered target site as the major mechanisms of resistance to pyrethroid insecticides in Ae. albopictus and Ae. aegypti. However, altered target site mechanism alone was found to be the major mechanism of resistance to pyrethroid in Ae. aegypti in Puerto Rico ${ }^{37}$. Multiple mechanisms could be present at the same time in resistant mosquitoes ${ }^{38}$, depending upon the history and geographical origin of insect strains. Future studies may be planned at molecular level to further confirm the mechanisms of resistance in Ae. albopictus.

Insecticide resistance is a major hindrance in the management of Aedes mosquitoes that ultimately lead to seasonal outbreaks of dengue fever in different areas of Pakistan. An important strategy could be to lessen the use of insecticides by adopting integrated vector management (IVM) tool such as mosquito-breeding source reduction, the use of mosquito nets, and management of rainwater collecting bodies. Aedes albopictus from different cities of Punjab, Pakistan, have shown resistance development to insecticides used for mosquito control, which may result in severe outbreaks of dengue fever in the future. To avoid this situation, regular insecticide resistance monitoring along with the use of alternative measures could be effective tools for managing Ae. albopictus.

Received: 6 August 2020; Accepted: 20 November 2020

Published online: 03 December 2020

\section{References}

1. Moyes, C. L. et al. Contemporary status of insecticide resistance in the major Aedes vectors of arboviruses infecting humans. PLoS Negl. Trop. Dis. 11, e0005625 (2017).

2. Kamal, M., Kenawy, M. A., Rady, M. H., Khaled, A. S. \& Samy, A. M. Mapping the global potential distributions of two arboviral vectors Aedes aegypti and Ae. albopictus under changing climate. PLoS ONE 13, e0210122 (2018).

3. Su, X. et al. Fast emerging insecticide resistance in Aedes albopictus in Guangzhou, China: Alarm to the dengue epidemic. PLoS Negl. Trop. Dis. 13, e0007665 (2019).

4. Ahmad, S. et al. Epidemiology of dengue in Pakistan, present prevalence and guidelines for future control. Int. J. Mosq. Res. 4, 25-32 (2017).

5. Khan, H. A. A. \& Akram, W. Resistance status to deltamethrin, permethrin, and temephos along with preliminary resistance mechanism in Aedes aegypti (Diptera: Culicidae) from Punjab, Pakistan. J. Med. Entomol. 56, 1304-1311 (2019).

6. Normile, D. Safety concerns derail dengue vaccination program. Science 358, 1514-1515 (2017).

7. Sever, H. C. et al. Recessivity of pyrethroid resistance and limited interspecies hybridization across Hyalella clades supports rapid and independent origins of resistance. Environ. Pollut. 266, 115074 (2020).

8. Heim, J. R. et al. Are there fitness costs of adaptive pyrethroid resistance in the amphipod, Hyalella azteca?. Environ. Pollut. 235, 39-46 (2018).

9. Brogdon, W. \& Chan, A. Guideline for evaluating insecticide resistance in vectors using the CDC bottle bioassay (CDC Atlanta, USA, 2010).

10. Khan, H. A. A. Susceptibility to indoxacarb and synergism by enzyme inhibitors in laboratory and field strains of five major stored product insects in Pakistan. Chemosphere 257, 127167 (2020)

11. Wilkinson, C. F. Insecticide Biochemistry and Physiology (Plenum Press, New York, 1976).

12. Sayyed, A. H., Pathan, A. K. \& Faheem, U. Cross-resistance, genetics and stability of resistance to deltamethrin in a population of Chrysoperla carnea from Multan Pakistan. Pestic. Biochem. Physiol. 98, 325-332 (2010).

13. Robertson, J., Russell, R., Preisler, H. \& Savin, N. (CRC Press, Taylor \& Francis, Berlin, Germany, 2007).

14. LeOra-Software v 1.0. (LeOra Software Petaluma, CA, 2005) https://leora-software.com/.

15. Mazzarri, M. B. \& Georghiou, G. Characterization of resistance to organophosphate, carbamate, and pyrethroid insecticides in field populations of Aedes aegypti from Venezuela. J. Am. Mosq. Control Assoc. Mosq. News 11, 315-322 (1995).

16. Flores, A. E. et al. Wide spread cross resistance to pyrethroids in Aedes aegypti (Diptera: Culicidae) from Veracruz state Mexico. J. Econ. Entomol. 106, 959-969 (2013).

17. Saeed, Q., Ahmad, F., Iqbal, N. \& Zaka, S. M. Chemical control of polyphagous pests on their auxiliary hosts can minimize insecticide resistance: a case study of Spodoptera exigua Hübner (Lepidoptera: Noctuidae) in cotton agroecosystem. Ecotoxicol. Environ. Saf. 171, 721-727 (2019).

18. Khan, H. A. A. Side effects of insecticidal usage in rice farming system on the non-target house fly Musca domestica in Punjab, Pakistan. Chemosphere 241, 125056 (2020).

19. Khan, H. A. A., Akram, W. \& Fatima, A. Resistance to pyrethroid insecticides in house flies, Musca domestica L., (Diptera: Muscidae) collected from urban areas in Punjab, Pakistan. Parasitol. Res. 116, 3381-3385 (2017).

20. Khan, H. A. A. Characterization of permethrin resistance in a Musca domestica strain: resistance development, cross-resistance potential and realized heritability. Pest Manag. Sci. 75, 2969-2974 (2019). 
21. Mohsin, M. et al. Susceptibility status of Aedes aegypti and Aedes albopictus against insecticides at eastern Punjab, Pakistan. MMJ 3, 41-46 (2016).

22. Arslan, A. et al. Spatial distribution and insecticide susceptibility status of Aedes aegypti and Aedes albopictus in dengue affected urban areas of Rawalpindi, Pakistan. J. Vector Borne Dis. 53, 136 (2016).

23. Hussain, N. J. N. Susceptibility of Laboratory-Reared Anopheles stephensi (Diptera: Culicidae) and Field-Collected Culex quinquefasciatus Larvae to Bacillus thuringiensis serovar israelensis and Bacillus sphaericus in Lahore, Pakistan. Pak. J. Zool. 43, 915-919 (2011).

24. Rathor, H. R., Nadeem, G. \& Khan, I. A. Pesticide susceptibility status of Anopheles mosquitoes in four flood-affected districts of South Punjab, Pakistan. Vector-Borne Zoonotic Dis. 13, 60-66 (2013).

25. Khan, H. A. A., Akram, W. \& Lee, S. Resistance to selected pyrethroid insecticides in the malaria mosquito, Anopheles stephensi (Diptera: Culicidae), from Punjab, Pakistan. J. Med. Entomol. 55, 735-738 (2018).

26. Tahir, H. et al. Toxicity and resistance of American cockroach, Periplaneta americana L. (Blattodea: Blattidae) against malathion. Afr. Entomol. 25, 361-366 (2017).

27. Khan, H. A. A., Akram, W., Shehzad, K. \& Shaalan, E. A. First report of field evolved resistance to agrochemicals in dengue mosquito, Aedes albopictus (Diptera: Culicidae), from Pakistan. Parasites Vectors 4, 146 (2011).

28. Vontas, J. et al. Insecticide resistance in the major dengue vectors Aedes albopictus and Aedes aegypti. Pestic. Biochem. Physiol. 104, 126-131 (2012).

29. Amelia-Yap, Z. H., Chen, C. D., Sofian-Azirun, M. \& Low, V. L. Pyrethroid resistance in the dengue vector Aedes aegypti in Southeast Asia: present situation and prospects for management. Parasites Vectors 11, 332 (2018).

30. Demok, S. et al. Insecticide resistance status of Aedes aegypti and Aedes albopictus mosquitoes in Papua New Guinea. Parasites Vectors 12, 333 (2019).

31. Marcombe, S. et al. Distribution of insecticide resistance and mechanisms involved in the arbovirus vector Aedes aegypti in Laos and implication for vector control. PLoS Negl. Trop. Dis. 13, e0007852 (2019).

32. Ponlawat, A., Scott, J. G. \& Harrington, L. C. Insecticide susceptibility of Aedes aegypti and Aedes albopictus across Thailand. J. Med. Entomol. 42, 821-825 (2005).

33. Chen, C. D. et al. Temephos resistance in field aedes (Stegomyia) albopictus (Skuse) from Selangor, Malaysia. Trop. Biomed. 30, $220-230$ (2013).

34. Kamgang, B. et al. Insecticide susceptibility of Aedes aegypti and Aedes albopictus in Central Africa. Parasites Vectors https://doi. org/10.1186/1756-3305-4-79 (2011).

35. Grisales, N. et al. Temephos resistance in Aedes aegypti in Colombia compromises dengue vector control. PLoS Negl. Trop. Dis. 7, e2438 (2013).

36. Smith, L. B., Kasai, S. \& Scott, J. G. Pyrethroid resistance in Aedes aegypti and Aedes albopictus: important mosquito vectors of human diseases. Pestic. Biochem. Physiol. 133, 1-12 (2016).

37. Hemingway, J., Boddington, R. G., Harris, J. \& Dunbar, S. J. Mechanisms of insecticide resistance in Aedes-Aegypti (L) (Diptera, Culicidae) from Puerto-Rico. Bull. Entomol. Res. 79, 123-130 (1989).

38. Hardstone, M. C. \& Scott, J. G. A review of the interactions between multiple insecticide resistance loci. Pestic. Biochem. Physiol. 97, 123-128. https://doi.org/10.1016/j.pestbp.2009.07.010 (2010).

39. Robertson, J. L., Jones, M. M., Olguin, E. \& Alberts, B. Bioassays with Arthropods (CRC Press, Boca Raton, 2017).

\section{Acknowledgements}

Sincere thanks to the laboratory attendants/students for help in insect collections and laboratory maintenance. The study was supported by the research funds of Institute of Agricultural Sciences (IAGS), University of the Punjab, Lahore.

\section{Author contributions}

H.A.A.K. planned and performed the experiments, analyzed the data and wrote the manuscript.

\section{Competing interests}

The author declares no competing interests.

\section{Additional information}

Supplementary information is available for this paper at https://doi.org/10.1038/s41598-020-78226-0.

Correspondence and requests for materials should be addressed to H.A.A.K.

Reprints and permissions information is available at www.nature.com/reprints.

Publisher's note Springer Nature remains neutral with regard to jurisdictional claims in published maps and institutional affiliations.

(c) (i) Open Access This article is licensed under a Creative Commons Attribution 4.0 International cc) License, which permits use, sharing, adaptation, distribution and reproduction in any medium or format, as long as you give appropriate credit to the original author(s) and the source, provide a link to the Creative Commons licence, and indicate if changes were made. The images or other third party material in this article are included in the article's Creative Commons licence, unless indicated otherwise in a credit line to the material. If material is not included in the article's Creative Commons licence and your intended use is not permitted by statutory regulation or exceeds the permitted use, you will need to obtain permission directly from the copyright holder. To view a copy of this licence, visit http://creativecommons.org/licenses/by/4.0/.

(C) The Author(s) 2020 